\title{
LA IMAGEN DE LOS GITANOS EN LA GINEMATOGRAFÍA RUMANA POSTCOMUNISTA
}

\author{
Valeriu Radulian, \\ Universidad de Alicante \\ valeriuradulian@yahoo.es
}

\section{RESUMEN}

Este artículo se propone analizar la imagen de los gitanos proyectada por los directores de cine rumanos en sus producciones postcomunistas. Para ello se pasa revista a los rasgos definitorios de los gitanos, de sus costumbres y su procedencia, como también a algunos criterios culturales que los diferencian de la población mayoritaria y dificultan su aceptación. Este enfoque argumenta la importancia de la integración de los gitanos en las sociedades europeas, a fin de dejar de representar un problema social y aboga por la necesidad de eliminar su marginación, lo cual, por otra parte, es una cuestión prioritaria en Europa.

Palabras clave: gitano, imagen, inclusión, exclusión, alteridad, mendicidad, cine rumano.

\section{INTRODUCCIÓN}

La inclusión o la exclusión de los gitanos son conceptos debatidos de modo especial en el actual contexto europeo. El mundo de los gitanos, tan controvertido, ha centrado y seguirá centrando la atención de muchos analistas literarios y sociales. La existencia de dicha etnia, o mejor dicho la coexistencia de la misma con las demás etnias no gitanas, ha generado a lo largo del tiempo toda una serie de situaciones conflictivas, cuyo punto neurálgico es, indudablemente, lo que llamamos la percepción de la alteridad; es decir, un mecanismo que pone en oposición la imagen sobre sí mismo y la imagen que el otro construye y proyecta sobre el que considera su alteridad.

Para ello, nos vamos a detener en el ciclo de cine rumano organizado a finales del 2015 por la Universidad de Alicante y el Instituto Cultural Rumano con la colaboración de la Asociación ARIPI, para tratar de observar cómo se presenta la imagen de esta etnia en las producciones cinematográficas rumanas postcomunistas, con especial hincapié en dos producciones que nos han parecido relevantes para el tema de este artículo: la película Filantropica, una producción rumano francesa del año 2002, en la que el imaginario 
colectivo sobre el gitano se relaciona con la mendicidad, y en Cómo celebré el fin del mundo, también producción rumano francesa, pero del año 2006, en la que se aborda la imagen del gitano desde la perspectiva del régimen comunista.

Mientras que en Cómo celebré el fin del mundo se narran los momentos justo antes de la caída del régimen del dictador Ceauşescu, en Filantropica se narran los efectos de la reinstauración del sistema capitalista, cuyo primer impacto provoca un desastre social y las aspiraciones de los rumanos son enriquecerse a cualquier precio, mientras que la mendicidad es un fenómeno en continua ascensión.

Aunque el gitano, en tanto que personaje de película, está presente en muchas producciones cinematográficas rumanas realizadas después de la caída del régimen comunista en diciembre de 1989, hay relativamente pocos estudios acerca de la imagen del mismo en la visión de los productores y realizadores rumanos. Este artículo pretende arrojar cierta luz a este respecto.

\section{RASGOS DEFINITORIOS, COSTUMBRES Y ORÍGENES DE LOS GITANOS}

Al optar por utilizar criterios objetivos a la hora de describir la etnia gitana (claro está, limitándonos a una conexión de tipo cultural) enfocando tanto los rasgos positivos, como los negativos, consideramos que en primer lugar habría que hacer una sucinta incursión en el mundo de las tradiciones y relaciones socio-históricas que ha ido forjando para comprender su simbología en las películas analizadas. Las preguntas que surgen de inmediato son: ¿Quiénes son los gitanos?, ¿de dónde vienen?, ¿qué idioma hablan? o ¿a qué se dedican?

La imagen de los gitanos sobre sí mismos está en un continuo proceso de definición y se vincula a la imagen que los demás proyectan permanentemente sobre ellos. No tienen una historia muy clara. Los investigadores que han analizado sus orígenes todavía mantienen dudas al respecto. Generalmente no se sabe de dónde vienen y aún más inciertas son las vías por las que llegaron a los países de acogida. Incluso hubo quienes se plantearon la pregunta de si los gitanos son un pueblo unido o son grupos que tienen varios rasgos en común. ¿Vienen todos estos grupos del mismo sitio? ¿Cuándo aparecieron? Muchas de las preguntas de este tipo siguen todavía sin respuesta.

Sin embargo, últimamente, la historia, la antropología y la lingüística han proporcionado herramientas a los investigadores para definir de alguna forma a la etnia gitana. La falta de documentos escritos relativos a la situación de los gitanos o la existencia de escasos textos, en general escritos por representantes de otras etnias, y no por los gitanos mismos, sugiere la posibilidad de que éstos contengan errores, detalles obviados o exageraciones deliberadas. Por otra parte, las traducciones o la transcripción repetida de dichos textos también podían ocasionar errores que hay que tener en cuenta a la hora de estudiar su historia.

De los datos recopilados para este artículo se desprende que la mayoría de los historiadores consultados coinciden en que los gitanos vienen de la región de Punjab, en el noroeste de la India, y se vieron obligados a salir de allí a causa de las persecuciones de los árabes, más o menos en torno al año 1000. Lograron llegar al continente europeo por dos vías, algunos por la costa mediterránea (el norte de África), mientras que otros llegaron a la Europa Central. En los siglos XV y XVI, había representantes de esta etnia en todos los países de Europa (Cherata, 1995). En cuanto a su primer contacto con los territorios rumanos, el historiador rumano George Potra (1939:11) afirma en Contribuţiuni la istoricul ţiganilor din 


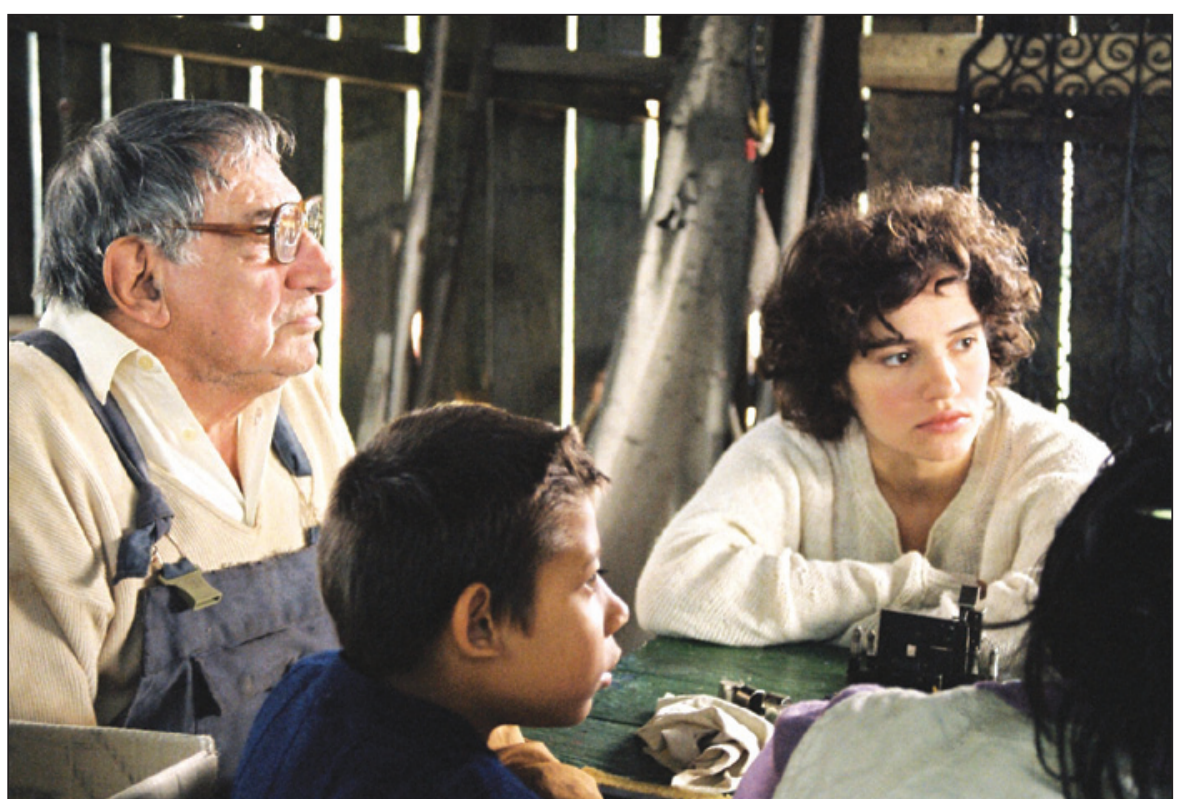

Cum mi-am petrecut sfârşitul lumii (Cómo celebré el fin del mundo, Cătălin Mitulescu, 2006).

România (Contribución a la historia de los gitanos de Rumanía) que quienes habían ido hacia el norte fueron fácilmente sometidos por los tártaros y junto con estos llegaron a los territorios rumanos. Esto es muy probable especialmente porque la aparición de los gitanos en los Países Rumanos coincide con la invasión tártara, a mediados del siglo XIII. Mihail Kogalniceanu (1976: 357), hombre político, abogado e historiador rumano, en su estudio «Esquisse sur I'histoire, les moeurs et la langue des Cigans connus en France sur le nom de Bohémiens», confirma la existencia en Hungría, en el año 1260, en tiempos del rey Bela IV, de un pueblo llamado Cingari, que había pasado de los Países Rumanos a la Hungría vecina.

Al principio, a los que llegaron al norte y al oeste de Europa se les llamaba romaniches, que significa amigo de los gitanos. En Francia y en España se les conocía como kales, que significa negro. Incluso hoy en día, en cada país se les conoce de manera distinta: Gypsies, en Gran Bretaña, bohemiens o gitans, en Francia, ţigani en Rumanía (que viene del griego athinganos), mientras que en España se les dice gitanos.

Algunas referencias más precisas parecen proceder del campo de la lingüística. Las únicas certidumbres pertenecen al campo de la lingüística y datan del siglo XVIII. Su descubrimiento se debe a la conexión que un estudiante húngaro de la Universidad de Leiden, Stephan Valyi, hizo con ayuda de tres compañeros indios de la región de Malabar, entre el idioma que ellos hablaban y el empleado por los gitanos. Partiendo de esta hipótesis los investigadores Rudiger y Grellmann de Alemania y Jacob Bryant de Inglaterra, han publicado varios estudios. Al analizar el idioma hablado por los gitanos de Alemania, Transilvania y Hungría, Grellmann descubrió en el plano léxico que muchas de las palabras eran de origen indio, mientras que sintácticamente había un gran parecido entre las reglas de conjugación rigiendo ambas lenguas. Unos años antes, Rudiger, analizando gramáticas publicadas en Europa, a finales del siglo XVIII, había llegado a la misma conclusión: los gitanos tienen orígenes indios.

¿A qué se dedican los gitanos? La mayoría son nómadas, aman la libertad de movimiento, aman los caballos, las carpas, los carros y todo lo que tiene que ver con la vida nómada. En lo que se refiere a sus profesiones, aun desde tiempos muy remotos, el imaginario colectivo 
solía diferenciar a los hombres de las mujeres. Los hombres eran ladrones, adiestraban animales y eran herreros, mientras que las mujeres adivinaban el futuro, leían las cartas, bailaban y cantaban. Al considerarse la magia una forma de estafa, esta práctica se asociaba automáticamente al robo. Miguel de Cervantes Saavedra consideraba que éste era el rasgo característico de los gitanos, afirmando que: «Nacen de padres ladrones, son criados en este sentido y aprenden a ser ladrones. Llegando a su madurez cometen robos a plena luz», en una de sus novelas ejemplares, La Gitanilla, de 1613. Varios siglos después, observamos que el imaginario colectivo no ha revisado o corregido esta etiqueta que estigmatiza y generaliza, por lo que la filmografía rumana postcomunista contiene algunos de los estereotipos perpetuados a lo largo de la historia.

La complejidad del tema y la necesidad de limitar este breve análisis nos obliga a hacer hincapié sólo en los elementos generales que describen la cultura y la forma de ser de los gitanos. Es muy difícil realizar una descripción real de esta etnia y, al mismo tiempo, expresar la variedad de las castas y sus puntos de vista. La forma de organización de los gitanos es por grupos, por lo que no se trata de una sociedad homogénea, sino de un mosaico en el que cada grupo conserva su propia personalidad. No todos los gitanos son nómadas y no todos los nómadas son gitanos. El nomadismo es un rasgo importante de los gitanos, pero no en el sentido general de la palabra. Sin embargo, fue un elemento decisivo a la hora de aclarar varias de sus características culturales (las leyes no escritas que guiaron a los gitanos por cientos de años). El paso a otro estilo de vida llevó, diacrónicamente, a un proceso progresivo de desagregación de esta conexión fundamental, de modo que el sedentarismo debilitó en alguna medida el poder de la tradición.

\section{EL FENÓMENO DE LA MENDICIDAD EN FILANTROPICA}

Volvamos ahora a las producciones cinematográficas rumanas posteriores a diciembre de 1989. Los directores de cine rumanos están presentes en casi todos los festivales internacionales y reciben importantes galardones. De hecho, la cinematografía rumana ha destacado siempre por su creatividad y originalidad, si bien durante la dictadura, su visibilidad internacional se veía mermada por la censura y los preceptos políticos que interferían en las artes, dictados por los órganos de propaganda del régimen. La nueva ola de cineastas rumanos, en palabras del influyente crítico de The New York Times, Tony Scott, es "la novedad más apasionante en el cine europeo desde España en los años ochenta» (La Vanguardia, 6 abril 2009). La diferencia consiste en que aquel nuevo cine español quiso pasar página cuanto antes del pasado dictatorial, mientras que la nueva ola rumana parece no haber tenido prisa alguna en dar por cerrada la crónica de la dictadura.

De esta forma surgieron películas como Filantropica. Después del comunismo y con la reinstauración del capitalismo, a medida que algunos se volvían ricos de la noche a la mañana, a través de métodos ilegales, otros se hundían en la pobreza. El fenómeno de la mendicidad, antes inexistente en el país (no porque no existiera la pobreza, sino porque tampoco se hubiera tolerado por las fuerzas del estado), se volvía cada vez más visible en tanto que problema social, la mayoría de las veces como una consecuencia de la pobreza. Pero se puede afirmar que la mendicidad es una característica de los gitanos y tal vez por esto más que nada se volvieron personajes omnipresentes en las producciones postcomunistas de los directores rumanos, expresiones culturales que se hacen eco de la nueva realidad. 


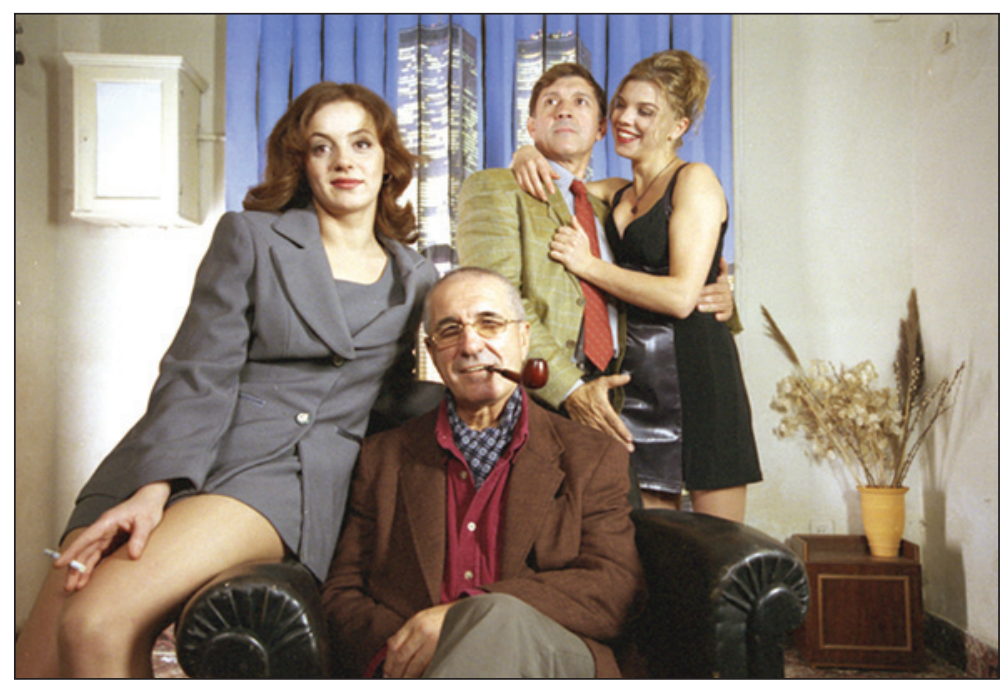

Filantropica (Filantropía, Nae Caranfil, 2002).

De hecho, el director Nae Caranfil enfatiza esta realidad en su película, deteniéndose en la situación económica bastante complicada de los rumanos en general y de algunos segmentos sociales desfavorecidos, en particular. El protagonista de esta película se llama Ovidiu y es profesor de secundaria. Anhela llegar a ser escritor. Vive con sus padres, que, al igual que todos los jubilados de la Rumanía postcomunista, son víctimas del constante empobrecimiento a raíz de la inflación y la desvalorización de sus ahorros o pensiones. Ovidiu ha pagado con sus ahorros la publicación de su libro de relatos, pero sin éxito, lo que le ocasiona una situación económica pésima. Todo esto sobre el fondo de unos sueldos paupérrimos del profesorado rumano de la enseñanza pública. Lo peor que le puede pasar es conocer a una chica hermosa que parece estar interesada en él: la hermana de uno de sus alumnos. El nivel de vida que le pide la muchacha es demasiado alto y eso le determina a buscar fuentes adicionales de ingresos, a pesar de que él ya estaba viviendo en condiciones extremadamente austeras. Caranfil transmite la idea compartida por parte de la sociedad rumana de que el capitalismo fabrica necesidades artificiales y las personas que se dejan arrastrar por él buscan conseguirlas a cualquier coste, olvidándose de sus principios. Ovidiu conoce más tarde a un poeta borracho que le habla de una sociedad cultural llamada Filantropica, que ayuda a la gente como él. En busca de una fuente de ingresos más consistentes que su propio sueldo, Ovidiu se adentra en el mundo de la mafia de los mendigos, mundo representado en la película por los gitanos.

La mendicidad es el método a través del cual una persona pide limosna o solicita el favor ajeno con insistencia y humillación. Se puede afirmar que la mendicidad se suele asociar a situaciones sociales de pobreza. También es practicada por personas que tratan de engañar a los demás en el sentido de que fingen ser pobres, pero en realidad tienen un nivel de vida aceptable. Los padres suelen implicar a los hijos en esta práctica de la mendicidad y hay que destacar que los menores desempeñan un papel clave a la hora de despertar sentimientos de lástima en los demás ciudadanos. La mujer con un niño en brazos inspira más ternura a la hora de pedir limosna, y por eso la imagen de la mujer en el ejercicio mendicante es más frecuente que la del hombre. Este desequilibrio, ya muy evidente entre los que no son gitanos, se agudiza más en el caso de esta etnia, en la que no se contempla apenas que los varones 
participen en la mendicidad. Los niños, víctimas de la manipulación familiar, son el grupo sobre el que se sustenta la mendicidad organizada. El componente infantil en la mendicidad familiar es preponderante, es el elemento básico que activa la atracción de la limosna, de modo especial los niños en edad lactante que son utilizados como elemento sensibilizador y como objeto de trabajo.

Esta es la clave de la película: el cambio producido por la reinstauración del sistema de explotación capitalista: el deseo de los rumanos de enriquecerse. El caso del profesor, que, por conquistar a la chica inaccesible, entra en la red mafiosa y se somete a las órdenes del gerente de la sociedad Filantropica, de la cual es prácticamente esclavo, representa una extraordinaria metáfora del nuevo sistema.

No se trata solamente de una crítica a la mendicidad, es más bien un retrato realista y crítico del sistema de valores que la produce: el capitalismo.

Filantropica es una película muy accesible y entretenida, en la que destacan el drama social más oscuro y la comedia negra de crítica social; en otras palabras, la difícil situación económica y social de Rumanía.

\section{LOS GITANOS EN LA ÉPOCA DEL DICTADOR NICOLAE CEAUŞESCU}

En Cómo celebré el fin del mundo el fenómeno de la mendicidad no está presente. A diferencia de Filantropica, la película narra la vida de los rumanos durante la época comunista y termina con la caída del régimen de Ceauşescu.

Sin embargo, la pobreza ha venido carcomiendo a la sociedad rumana durante la etapa comunista. Esta circunstancia determina que muchos sueñen con evadir aquella realidad huyendo a los países occidentales. Eva vive con sus padres y su hermano de siete años. Enamorada por primera vez, sueña con salir de Rumanía y viajar. El pequeño, que conoce su deseo secreto, teme que su hermana pueda dejarle y con dos amigos trama un plan para que Eva pueda quedarse: matar al dictador. Es un retrato de los últimos meses de la dictadura de Ceauşescu, sugeridos por el director a través de las vicisitudes de Eva, una adolescente con deseos de liberarse del ambiente represivo (social, familiar, escolar) en que vive, y a través de las relaciones que entabla con los miembros de su familia -particularmente con su hermano pequeño- y con sus vecinos, especialmente con Alex y Andrei, dos jóvenes de su edad pertenecientes el uno a la clase dirigente y el otro a la disidencia al régimen comunista, respectivamente. Entre los compañeros del hermano de Eva vemos también a algunos de etnia gitana, $y$, a diferencia de otras representaciones estereotipadas, hay gitanos trabajando, pero como la película está ambientada en tiempos del régimen comunista, los gitanos están aparentemente integrados y decimos aparentemente porque, si bien el régimen alardeaba de sus políticas sociales inclusivas, en realidad el estigma patente o subyacente marcaba la convivencia. Esta fingida integración se observa también en la película, cuando alumnos y profesores preparan las canciones para el congreso del dictador, y un compañero de clase de Lalalilu, gitano, le dice al profesor que él también podría cantar, pero es rechazado por un motivo tan excluyente como cínico en su verbalización: a él no se le puede llevar a la festividad. Esta discriminación parece asumida con naturalidad por todos, incluido el niño gitano, por lo que deducimos que subyace en la sociedad.

Paradójicamente, reconstituir la historia de los gitanos de la época comunista es incluso más difícil que establecer con exactitud quiénes son y de dónde vienen. Por mucho tiempo, en 
Rumanía no hubo una política especial en lo que se refiere a los gitanos. A finales de los años setenta y comienzos de los ochenta, las autoridades se plantearon encontrar una solución a la difícil situación social en que se encontraban los representantes de esta comunidad, y diseñaron políticas que no fueron reveladas. Las estadísticas, las decisiones tomadas en los foros políticos y administrativos, hasta donde hemos podido investigar, no se hicieron públicas.

En cuanto a las condiciones de vida, en los años del socialismo, los gitanos han progresado sin lugar a dudas. Las chozas en las que vivían los gitanos, en las afueras de las grandes ciudades, hasta los años sesenta no desaparecieron por completo, pero su número bajó considerablemente. La obligación de trasladar a los gitanos a los edificios de viviendas construidos por los comunistas representó un paso importante hacia un mínimo de confort.

Hasta los años sesenta, el igualitarismo del período comunista permitió a los gitanos tener representaciones de identidad mínimas (música en romani, libros, etc.) y, en cierta medida, tener acceso a los recursos y a los servicios sociales, lo que ocasionó una mejora de su estatuto socio económico.

La movilidad social creó las premisas de una élite que, por un lado se había integrado en la cultura mayoritaria y por otro lado representaba tácitamente un modelo de referencia para la etnia. Simultáneamente, en el período 1950-1970 continuaron las medidas de sedentarización forzada, fue prohibido el nomadismo así como la práctica de sus oficios itinerantes.

En los años ochenta, el Partido Comunista lanzó el programa nacional La integración de los gitanos, desarrollado a través del Ministerio del Interior, pero únicamente contemplaba realizar un censo de los gitanos y combatir los delitos cometidos por los mismos. Inmediatamente después, en un marco general de las políticas para las minorías, indistintamente de su nacionalidad, la minoría gitana desaparece incluso en tanto que entidad implícita. Para acceder a un estatuto superior, la única posibilidad era la naturalización, renunciando a su identidad étnica, lo que supuso una disminución de la alteridad y el aumento de los prejuicios raciales. Desde el punto de vista cultural y social, los gitanos eran considerados una subcultura parasitaria, un grupo social marginal.

Había gitanos que continuaban con los oficios específicos, pero en el nuevo contexto económico muchos se vieron obligados a abandonar estas artesanías y dedicarse a oficios modernos. Por ejemplo, los herreros buscaron puestos de trabajo en la industria pesada o en las construcciones, los gitanos que vivían en las aldeas de la periferia de la capital tuvieron que dedicarse a la albañilería. Un número importante de gitanos fue contratado por las empresas que se dedicaban a la salubridad de la capital y de las grandes ciudades.

El mensaje de ambas películas es muy fuerte, aunque la acción transcurre en momentos distintos, es decir en tiempos del comunismo (Cómo celebré el fin del mundo) y en tiempos del nuevo capitalismo (Filantropica). Como el ciclo de cine rumano fue presentado en España, todas las películas fueron subtituladas, traducidas al español, un proceso nada fácil si tenemos en cuenta que se tienen que traspasar barreras lingüísticas y diferencias culturales.

Una descripción atenta y una visión del conjunto nos ayudan a comprender que cada ser humano, indistintamente de su etnia, tiene su lugar en este mundo.

Todos somos como las piezas de un rompecabezas. Cada persona, única en su forma de ser, puede contrastar con su vecino, pero la existencia de cada uno cobra sentido únicamente en la colectividad.

Otra comparación, que sirve perfectamente para las conclusiones de este artículo, es la similitud de las personas con las piezas de un tablero de ajedrez. Cada pieza tiene su papel 
muy bien definido, pero la misma se puede mover únicamente en función de las demás piezas del tablero, cumpliendo con ciertas reglas. De la misma forma, los gitanos no pueden ser ignorados o excluidos de los países en que viven.

\section{BIBLIOGRAFÍA}

CARVALHO, Antonio, Historia de los gitanos, Barcelona, Sabrat, 1992.

CERVANTES SAAVEDRA, Miguel, Novelas Ejemplares, Madrid, Colección Austral, 1975.

CHERATA, Lucian, Istoria ţiganilor, Bucarest, Ed. Z, 1995.

KOGALNICEANU, Mihail, Opere, vol II, Bucarest, ed. Academiei, 1976, pág. 357.

POTRA, George, Contribuţiuni la istoricul ţiganilor din România, Bucarest, ed. Fundaţia Regală, 1939, pág. 11.

\section{Páginas de internet}

<http://www.lavanguardia.com/cultura/20090406/53676352680/el-encanto-del-cinerumano.html> [consulta: 20 marzo 2016]. 